\title{
Process-Functional Model of Transportation Mix Concrete
}

\author{
Andrey Vladimirovich Ostroukh1, Bashmakov Igor Aleksandrovich², \\ Polgun Mikhail Borisovich ${ }^{3}$ \\ ${ }^{1}$ Department of Automated Control Systems, Moscow Automobile \& Road Construction State Technical \\ University, Moscow, Russia \\ ${ }^{2}$ Department of Management, Moscow Automobile \& Road Construction State Technical University, Moscow, \\ Russia \\ ${ }^{3}$ Department of Automated Control Systems, Moscow Automobile \& Road Construction State Technical \\ University, Moscow, Russia \\ Email: ostroukh@mail.ru, bashmakov-igor@rambler.ru, lomomike@rambler.ru
}

Received 4 November 2013; revised 5 December 2013; accepted 2 January 2014

Copyright (C) 2014 by authors and Scientific Research Publishing Inc.

This work is licensed under the Creative Commons Attribution International License (CC BY).

http://creativecommons.org/licenses/by/4.0/

c) (i) Open Access

\section{Abstract}

The paper proposes a process-functional model of transportation mix concrete, which is a structured description of a means of transportation technology mix concrete road at the level of the production process. Range of activities related to the transportation of concrete mixtures is presented in the form of hierarchically nested processes that are coordinated on the basis of general systems theory. The model is described in a strict sequence: process chain $\rightarrow$ process step $\rightarrow$ process link, and all built technological chains consist of indivisible units.

\section{Keywords}

Road Transport, Process Chain, The Transport Process, Transportation of Concrete Mixes

\section{Introduction}

Currently, despite the widespread use of monolithic construction, there are very few methodological developments aimed at improving the delivery of the transport process of concrete mixtures [1]-[3]. In turn, this is due to the need to address a number of indicators for transport of concrete mixtures:

1) It must be done in a given time frame;

2) To specify the beginning and the same is true in the quality of the mixture during transport;

3) Proper use of concrete, due to the fact that it is irrevocably lost after laying their former properties and ac-

How to cite this paper: Ostroukh, A.V., Aleksandrovich, B.I. and Borisovich, P.M. (2014) Process-Functional Model of Transportation Mix Concrete. Journal of Transportation Technologies, 4, 157-163.

http://dx.doi.org/10.4236/itts.2014.42016 
quire new one after concrete mixture placement.

It is quite difficult to develop a methodology which is capable to take into account all of the performance and improve the performance of the technology "production-transportation-consumption", but it is possible if we consider the models, methods and tools, motor maintenance construction industries as an interrelated set of tasks of production, transportation and use of concrete mixtures, materials and building products to construction sites.

A significant effect can be obtained as a result of the submission process of building materials, including concrete mixtures as a basic component of cast reinforced concrete construction, transporting them on objects and Works complex - as a single chain of interconnected subsystems of [4]-[25] and also in the development of new methods and models for motor maintenance, reducing occupational hazards.

\section{Model Transporting Concrete Mixtures Road}

Transportation technology mix concrete roads are invited to submit in the form of hierarchically nested processes performed by the method of tuples [3]-[5]. Ordered set of phases in the process of organizing model of the primary action to change the subject of work in the state of technology is a Link, the phases of which have a direct, i.e. indissoluble relation to each other (Figure 1). This process is not subject to further decomposition and is a primary element of any work in the transportation technology of concrete road. Each phase in the tuple is a special place with rigidly deterministic interfacial bonds in the form of mutual obligations that are not violated.

Here:

f1, 2,3 - sequence number of the phase tuple;

c1, 2,3 - ordinal designation tuple connection phases;

o1, 2,3-feedback between phases tuple;

$\mathrm{x} 1, \mathrm{y} 1, \mathrm{z} 1$-phase process conveying concrete mixture, for example: $\mathrm{x} 1$-departure loaded vehicle with the concrete mixing plant, $\mathrm{y} 1$ - following the vehicle to the object being built, $\mathrm{z} 1$ - the arrival of the vehicle to a new project .

Next, the technique of the organization process chain "production-transportation-consumption", which provides a coordinated functioning of all parts , the application of which the process of forming a plurality of tuples, and correspondences between the elements of the system is set up the transformation of the object of labor in the labor product or commodity [1]-[5]. Model tuples formed as long as all the operations necessary for transportation of concrete mixtures node in concreting unit will not be structured.

Central feature sets in the model as a set of processes is determined by its relationship with the set of tuples consistent (Figure 2), which reflect all the considered technology.

Here the links reflect the specific content of the stages of transportation technology of concrete road:

Link 3: step of loading the concrete mix into the vehicle;

Link 4: transportation of concrete to the object under construction;

Link 5: unloading of concrete on a construction site.

This acyclic network, and it actually has a semantic network using an interpretation of the relationship of nodes of the graph as "part-whole" that reflects the content of the technological chain link tuples describing the technology of transportation mix concrete trucks.

Decomposition of the object of research on functional subsystems is performed by using basic functional model of the process (Figure 3). It is a combination of minimum basic elements of the process model of the tuple in detail describing the above technology.

Principles of parametric optimization of subsystems and procedures for the selection of the parameters in multicriteriality, uncertainties and production risks are:

1) when the ratio of "one-to-many": $\mathrm{N} 1$ = (Xi, fi)—element "entry"; $\mathrm{N} 2=(\mathrm{fi}, \mathrm{Yi})$ —element "out"; $\mathrm{N} 4=(\mathrm{K}$, fi) — the element of "control"; N5 = (M, fi)—an element of the "mechanism";

2) in respect of the "many-to-many": N3 = (Xi, Yi —item "action".

Here:

$\mathrm{Xi}$-accumulated a lot of items of work (technology-related transportation of concrete mixes) used as part of the "input" (accumulation);

$\mathrm{Yi}-\mathrm{a}$ lot of converted objects of labor (also related to the transportation technology of concrete mixtures) used as part of the "exit" (conversion);

fi-operation used as part of the "action" (moving);

$\mathrm{K}$ - a set of data objects that are used as part of the "control"; 


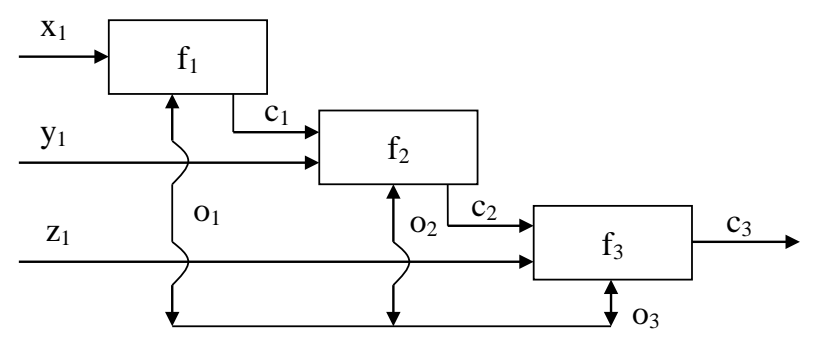

Figure 1. Process model of the Link.

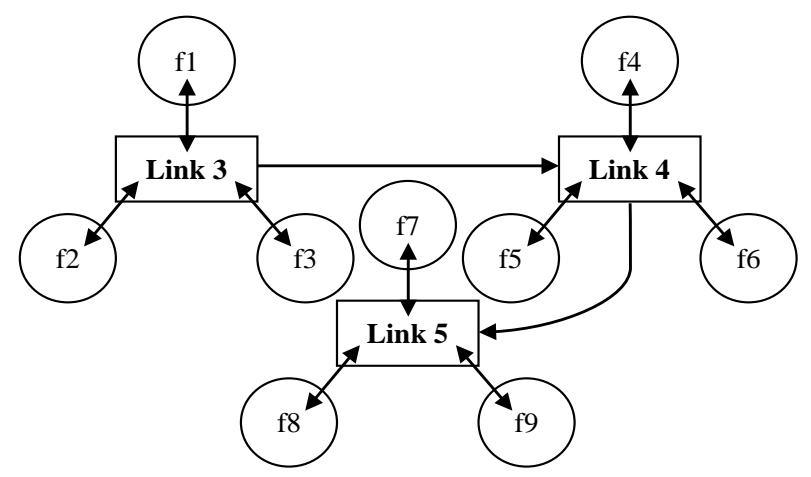

Figure 2. Relationship of Links.

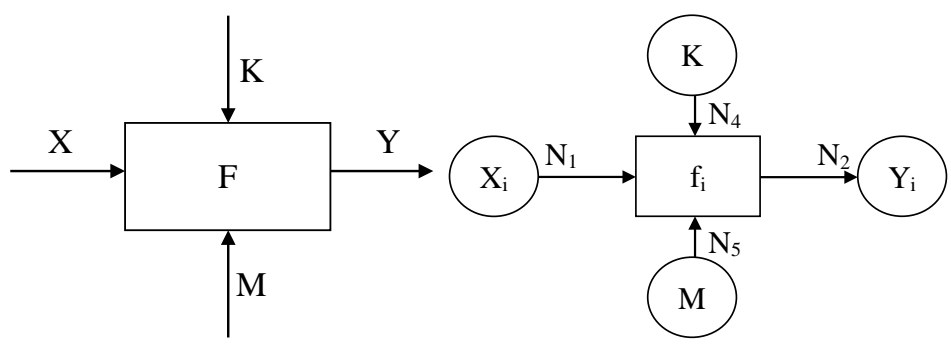

Figure 3. Elementary functional model of the process.

M-set of elements of transport structures used as part of the "mechanism for moving the object of labor".

Thus, the system-wide study is performed, allowing presenting a set of works in the form of hierarchically nested processes that are coordinated on the basis of general systems theory.

\section{Determining the Reliability of Transportation Technology of Concrete Mixtures}

Reliability of the system is the likelihood that the operation under given conditions the system will satisfactorily perform the desired functions within a specified time interval. Reliability indices processes with probabilistic data values are in the range $0 \leq \mathrm{P} \leq 1$. The " 0 " is an indication of the complete cessation of functioning, and " 1 " -an indicator of the total interaction. The process of transporting the concrete mix was used to determine the quality of their work such indicators as: stability, reliability, recoverability. Reliability affects in this case the resilience of the system is on. Because the technology of transportation of concrete mixtures can be viewed as a process, it is permissible to express the reliability of using a formula.

Reliability technology transportation of concrete mix for some time $t$ is completely specified function $R(t)$, if we know the function of the reliability of individual stages of this technology, i.e.:

$$
R(t)=\prod_{i=1}^{n} R_{m}(t),
$$

$R_{m}(t)$ - the reliability of individual units transporting concrete technology. The reliability of these phases is calculated based on the number of risks identified and registered. To calculate $R_{m}(t)$ uses statistical data. The 
formula for calculating $R_{m}(t)$ :

$$
R_{m}(t)=e^{-\lambda t}
$$

$\lambda$-risk ratio for a particular stage of concrete transportation technology; $t$-duration of a certain stage of the transport technology of concrete mix $(h) ; m$-number of stages.

$$
\lambda=\frac{f}{h_{c p i}},
$$

$f$-total standard deviation on to consider the risk to the adoption in the calculation of their probabilities; $h_{c p i}$-average probability of the $i$-th risk.

$$
f=\sqrt{\frac{\sum_{i=1}\left(h_{o p t i}-h_{c p i}\right)^{2}}{n}}
$$

$H_{\text {opti }}$-optimized the probability of the $i$-th risk; $h_{c p i}$-average probability of the $i$-th risk; $n$ —amount accounted risk Link.

\section{Modern Automated Dispatching Control Systems}

Automated dispatching control systems (ADCS) of motor transport park are built on the basis of satellite navigation. The primary assignment of such systems is reliability support of centralized transport facility park control on industrial enterprise. ADCS solves next problems [21] [22].

1) Improving scheduling and scheduled transport operations execution, improving enterprises production transportation;

2) Efficiency increase of transport facility use (decrease of involuntary loss of time on a line; sustainable rolling-stock and stockpile use and, as a consequence of this, decrease of transport maintenance costs);

3) Increase of operation safety of enterprises motor transport.

Notion of control point (CP) lies in the heart of transportation planning subsystem operation of modern dispatching system. Control point is some spot of area, which preset required transport facility passage point (Figure 4).

Control points are used for transportation plans compound (TF should pass defined arranged set of CP's in a given time) and for TF's actual movement evaluating [4]-[25].

Different real infrastructure objects can be represented in the form of CP (objects of: load/off-load, filling/drain, construction, petrol station, etc.). When TF's navigational coordinate came into ADCS, system verifies its entry to each of polygon. Determination process of CP with its navigational coordinate calls "linkage" of navigational coordinate and CP [6]. CP can be composed of polygon or geometric primitive: triangles, rectangles, parallel-grams, circumferences. If CP consists of several primitives, then it's called complex Control Point. CP's area is a primitive pack area which compounds current CP.

A "Ray tracing method" can be used for navigational coordinate ingress of CP's area evaluation (Figure 5).

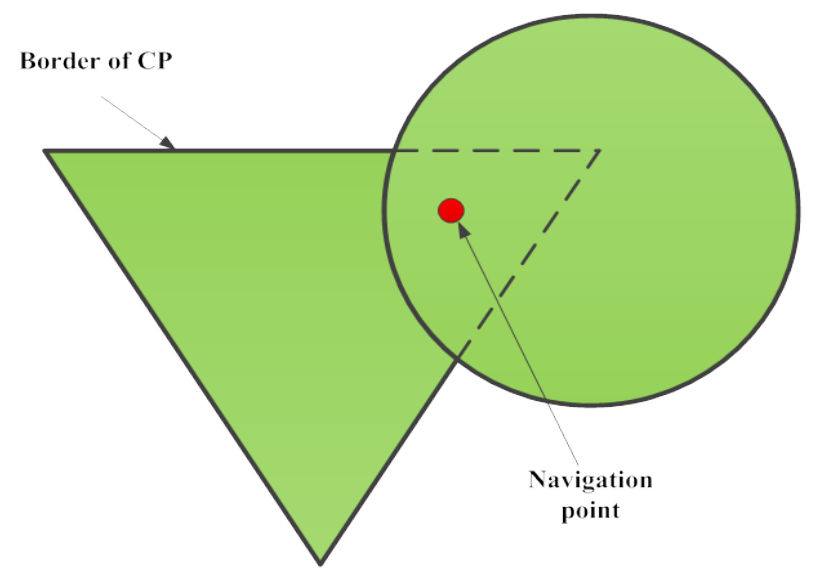

Figure 4. A hit of navigation point on CP. 


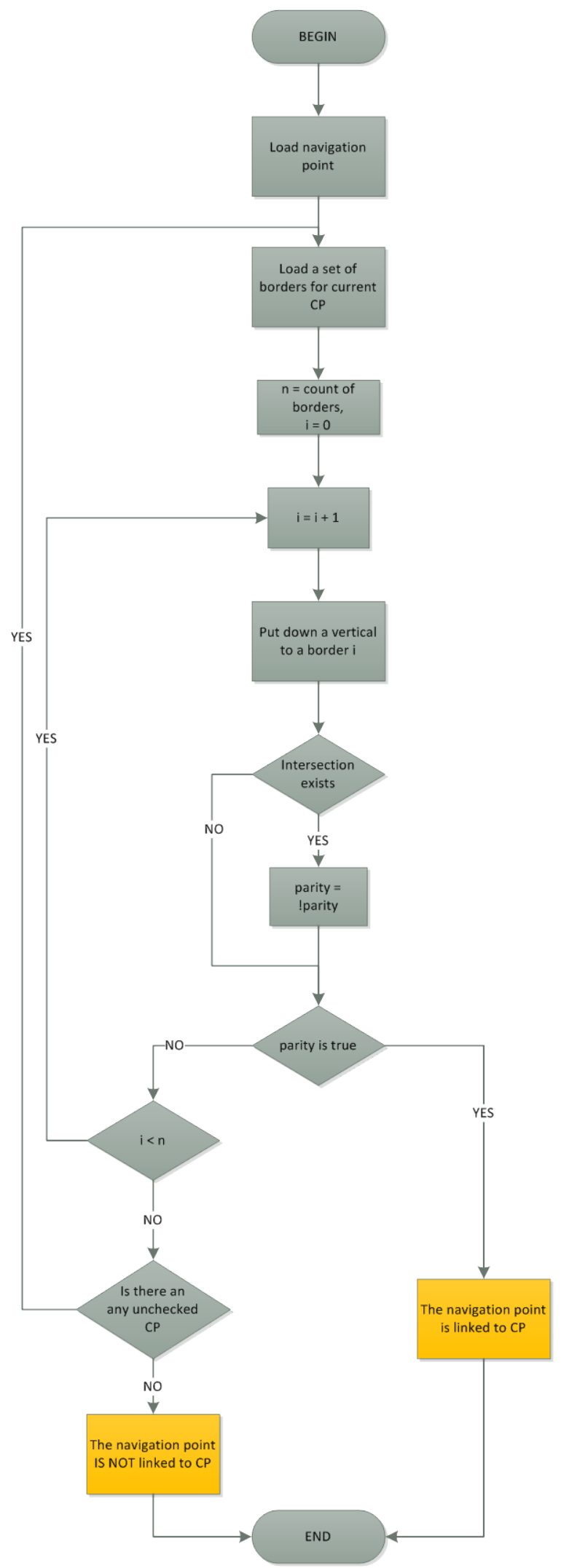

Figure 5. Algorithm of linkage of navigation point ad CP. 
This algorithm is used in computational geometry for spot ingress of closed polygon evaluation, but it doesn’t take into account inaccuracies which are concerned with navigational equipment operation.

These inaccuracies can be neglected, as CP's areas rarely can be more than 500 meters. So the effect of cartographic projection distortion wouldn't make large inaccuracies in such scales [6].

During ACDS operation system marks CP's with their navigational coordinates, if they have once. It is called CP's include. Include shows which of CP's were passed by TF's and which of CP's appeared "false". This approach is based on TF's time spent on CP evaluation. From data included and false CP's, ACDS allows to define actual value of fulfilled transport work, and it can also compare findings with planned values which were specified before TF's leave on a line.

CP's use has been shown itself as a good approach, but it doesn't have only advantages. The main disadvantages of CP's approach are [10]:

- Manual input. Enterprise dispatching centers specialists mark CP's by hand. This process is laborious, monotonous and tiring. Therefore a human element influences on efficiency.

- CP's are static. Once entered in a database CP's can be only updated or deleted, but it practically never happens. If such system would be scaled to a region wide or countrywide coverage, then data in a database would take much space that entails systems slow operation.

- CP's are discrete and detached. CP sets fixed area. If TF passed not through defined CP in some reason, it means that transportation plan was disrupted. Though it couldn't be so in some reasons.

- From all observations above it is suggested to swerve from static manual transportation planning to automatic dynamic planning. It doesn't mean that human element would be fully excluded. It is impossible. But human element influence would be minimized.

\section{Conclusions}

System-wide developmental work has been carried out, which allows presenting work package in the form of hierarchically embedded processes that are coordinated on the basis of general systems theory.

The proposed technique is based on the model of tuples. As a result, it becomes possible to identify production risks. Choice of risks that should be minimized passes with using an expert method based on the situational model.

Quick and regular transportation and off-load of manufactured production are important constituents of industrial enterprise successful work. The main load in this task lays on automotive transport, which is optimal from different points of view. An enterprise should consider a lot of factors for high-quality transportation, among them: transportation costs, prompt delivery, constantly changing traffic situation.

\section{References}

[1] Bashmakov, I.A. and Pokrovsky, A.K. (2010) Mathematical Models in Risk Management of Transport Companies. Cargo and Passenger Car Fleet, 1, 30-33.

[2] Bashmakov, I.A. and Pokrovsky, A.K. (2011) On the Reliability and Risks in Transport Companies. Cargo and Passenger Car Fleet, 1, 66-69.

[3] Bashmakov, I.A., Pokrovsky, A.K. and Komarov, A.A. (2012) The Risks of Production Processes. Transport: Science, Technology, Management, 1, 65-67.

[4] Kuznetsov, I.A. and Ostroukh, A.V. (2008) Features of the Implementation of Automated Information-Analytical Center of the Transport Planning of Construction Materials. Vestnik MADI (STU), 1, 92-96.

[5] Vlasov, V.M. (2006) Information Technology in Road Transport. In: Prikhodko, V.M., Ed., Under Society, Nauka, Moscow, 283.

[6] Vlasov, V.M., Ephimenko, D.B. and Ozherel'ev, M.Y. (2005) Comparative Analysis of Supervisory Systems Ground Transportation (Traditional and Using Satellite Navigation). Vestnik MADI (STU), 1, 110-115.

[7] Przhibyl, P. and Svitek, M. (2003) Transport Telematics. MADI (STU), 1, 540.

[8] Vlasov, V.M. (2003) Telematics in Road Transport. MADI (STU), 1, 173.

[9] Polgun, M.B., Vorobyova, A.V. and Ostroukh, A.V. (2011) Analysis Models Dispatching Control Urban Passenger Transport. Young Scientist, 3, 9-13.

[10] Ephimenko, D.B., Gubanov, A.I., Nikolaev, A.B. and Ostroukh, A.V. (2011) Automated Navigation System Supervisory Control and Accounting of Transport Oil Producing Companies. Young Scientist, 3, 18-21. 
[11] Ephimenko, D.B., Ostroukh, A.V. and Filatov, S.A. (2011) Development of a Navigation System Dispatching Freight Transport (For Example, Oil-Producing Enterprises). Transport Company, 1, 32-34.

[12] Ephimenko, D.B., Ostroukh, A.V., Nikolaev, A.B. and Gubanov, A.I. (2011) The Concept of Automated Navigation System Supervisory Control and Accounting of Transport Oil Producing and Refining Companies. Automation and Remote Control of the Connection to the Oil Industry, 1, 12-14.

[13] Ostroukh, A.V., Nikolaev, A.B., Ephimenko, D.B. and Zhankaziev, S.V. (2011) Scientific Approach to the Development of an Automated Navigation System, Supervisory Control and Accounting of Transport Oil Producing and Refining Companies. Automatic Control Systems and Automation Devices, 1, 48-58.

[14] Ostroukh, A.V. and Kuftinova, N.G. (2012) Automation of Planning and Management of the Transportation of Production for Food Processing Industry Enterprises. Automatic Control and Computer Sciences, 46, 41-48. http://dx.doi.org/10.3103/S0146411612010063

[15] Kuftinova, N.G. and Ostroukh, A.V. (2012) Automation Planning and Transportation Management Products of the Food Industry. Automation and Computer Engineering, 6, 57-67.

[16] Porfir'eva, S.A., Ostroukh, A.V., Danchuk, K.A., Lvova, A.B. and Yakunin, P.S. (2012) Automated Information Systems Transport Enterprise. In the World of Scientific Discoveries, 26, 34-38.

[17] Ephimenko, D.B., Ostroukh, A.V., Nikolaev, A.B. and Ismailov, A.R. (2012) Using the Software Radio Navigation Systems for Vehicle Dispatching Service Special Facilities of Oil Companies. Transport Company, 1, 42-44.

[18] Kuftinova, N.G. and Ostroukh, A.V. (2013) Development of Information-Logical Model of the Transport Network Metropolis. Bulletin of Transport Information, 1, 23-26.

[19] Ostroukh, A.V., Polgun, M.B., Nikolaev, A.B. and Ephimenko, D.B. (2013) Process Automation Supervisory Control Urban Passenger Transport. Industrial ACS and Controllers, 1, 10-16.

[20] Ismailov, A., Lvova, A., Nikolaev, A. and Ostroukh, A. (2013) Organization and Management of Transport Provided for the Guests and Participants of the Olympic Games. Middle-East Journal of Scientific Research, 17, 1098-1104.

[21] Polgun, M.B. (2012) Analysis of the Structure of Information Security of Automated Supervisory Systems Urban Passenger Transport. Automation and Control in Technical Systems, 12, 129-135.

[22] Polgun, M.B. (2013) New Approaches to the Development of Automated Supervisory Systems Transport Industrial Enterprise. Automation and Control in Technical Systems, 4, 81-90. http://dx.doi.org/10.12731/2306-1561-2013-4-15

[23] Kuftinova, N.G. and Ostroukh, A.V. (2011) Automation of Transportation. LAP LAMBERT Academic Publishing, Saarbrucken.

[24] Ostroukh, A.V., Krupenskii, N.A. and Ivakhnenko, A.M. (2013) Operational Control Forwarding Activities. Process Approach to Aggregation System Performance Forwarding Enterprise. Palmarium Academic Publishing, Saarbrucken.

[25] Nikolaev, A.B. and Ostroukh, A.V. (2013) Information Technology in Management and Transport Logistics: A Tutorial. Publishing House Science and Innovation Center, St. Louis. 